\title{
Comparison of cross-sectional imaging techniques for the detection of prostate cancer lymph node metastasis: a critical review
}

\author{
Amir H. Lebastchi ${ }^{1 \#}$, Nikhil Gupta ${ }^{1 \#}$, John M. DiBianco ${ }^{2}$, Morand Piert ${ }^{3}$, Matthew S. Davenport ${ }^{3}$, \\ Michael A. Ahdoot ${ }^{1}$, Sandeep Gurram ${ }^{1}$, Jonathan B. Bloom ${ }^{1}$, Patrick T. Gomella ${ }^{1}$, Sherif Mehralivand ${ }^{4}$, \\ Baris Turkbey ${ }^{4}$, Peter A. Pinto ${ }^{1}$, Arvin K. George ${ }^{3}$ \\ ${ }^{1}$ Urologic Oncology Branch, National Cancer Institute, National Institutes of Health, Bethesda, MD, USA; ${ }^{2}$ Department of Urology, George \\ Washington University Medical School, Washington D.C., USA; ${ }^{3}$ Department of Urology, University of Michigan, Ann Arbor, MI, USA; ${ }^{4}$ Molecular \\ Imaging Program, National Cancer Institute, Bethesda, MD, USA \\ Contributions: (I) Conception and design: AH Lebastchi; (II) Administrative support: None; (III) Provision of study materials or patients: None; (IV) \\ Collection and assembly of data: AH Lebastchi, N Gupta; (V) Data analysis and interpretation: AH Lebastchi; (VI) Manuscript writing: All authors; \\ (VII) Final approval of manuscript: All authors. \\ "These authors contributed equally to this work. \\ Correspondence to: Amir H. Lebastchi, MD. Urological Oncology Branch, National Cancer Institute, NIH, 10 Center Drive, Building 10 Room 1-5940, \\ Bethesda, MD 20892-1208, USA. Email: Amir.Lebastchi@nih.gov.
}

\begin{abstract}
Conventional staging for prostate cancer (PCa) is performed for men diagnosed with unfavorable-intermediate or higher risk disease. Computed tomography (CT) of the abdomen and pelvis and whole body bone scan remains the standard of care for the detection of visceral, nodal, and bone metastasis. The implementation of the 2012 United States Preventive Services Task Force recommendation against routine prostate specific antigen (PSA) screening resulted in a rise of metastatic PCa at the time of diagnosis, emphasizing the importance of effective imaging modalities for evaluating metastatic disease. CT plays a major role in clinical staging at the time of PCa diagnosis, but multi-parametric magnetic resonance imaging (MRI) is now integrated into many prostate biopsy protocols for the detection of primary PCa, and may be a surrogate for CT for nodal staging. Current guidelines incorporate both CT and MRI as appropriate cross-sectional imaging modalities for the identification of nodal metastasis in indicated patients. There is an ongoing debate about the utility of traditional cross-sectional imaging modalities as well as advanced imaging modalities in detection of both organ-confined PCa detection and nodal involvement.
\end{abstract}

Keywords: Prostate cancer (PCa); metastatic prostate cancer; lymph nodes (LNs); magnetic resonance imaging (MRI); computed tomography (CT)

Submitted Oct 21, 2019. Accepted for publication Feb 25, 2020.

doi: $10.21037 /$ tau.2020.03.20

View this article at: http://dx.doi.org/10.21037/tau.2020.03.20

\section{Introduction}

Conventional staging for prostate cancer (PCa) is performed for men diagnosed with unfavorable-intermediate or higher risk disease (Table 1). Computed tomography (CT) of the abdomen and pelvis and bone scan remain the standard of care for the detection of visceral, nodal, and bone metastasis. However, these studies provide limited information regarding local staging that can inform risk and guide treatment, specifically intraoperative decision making.

Accurate knowledge of lymph node (LN) involvement is important to counsel and determine a treatment plan for the patient. While the pathological assessment of LN following surgical dissection is the most accurate assessment of pelvic $\mathrm{LN}$ involvement in PCa, surgery may not be indicated in the 
Table 1 Prostate cancer risk categories

\begin{tabular}{|c|c|c|c|}
\hline Categories & $\mathrm{NCCN}$ & AUA & EAU \\
\hline Low & $\begin{array}{l}\mathrm{PSA}<10 \mathrm{ng} / \mathrm{mL} \text {, and GGG } 1 \text {, and clinical } \\
\text { stage T1-T2a }\end{array}$ & $\begin{array}{l}\mathrm{PSA} \leq 10 \mathrm{ng} / \mathrm{mL} \text {, and GGG } 1 \text {, and clinical } \\
\text { stage } \mathrm{T} 1-\mathrm{T} 2 \mathrm{a}\end{array}$ & $\begin{array}{l}\mathrm{PSA}<10 \mathrm{ng} / \mathrm{mL} \text {, and } \mathrm{GS}<7 \\
\text { (ISUP grade } 1 \text { ), and cT1-2a }\end{array}$ \\
\hline Intermediate & $\begin{array}{l}\text { Favorable intermediate: } 1 \text { IRF, and GGG } 1 \\
\text { or } 2 \text {, and }<50 \% \text { biopsy cores positive }\end{array}$ & $\begin{array}{l}\text { - Favorable intermediate: GGG 1, or } \\
\text { GGG } 2 \text { (with PSA <10) }\end{array}$ & \\
\hline \multirow[t]{2}{*}{ High } & $\begin{array}{l}\mathrm{PSA}>20 \mathrm{ng} / \mathrm{mL} \text {, or } \mathrm{GGG} 4 \text { or } 5 \text {, or clinical } \\
\text { stage T3a }\end{array}$ & $\begin{array}{l}\mathrm{PSA} \geq 20 \mathrm{ng} / \mathrm{mL}, \text { or } \mathrm{GGG} 4-5, \text { or clinical } \\
\text { stage } \geq \mathrm{T} 3\end{array}$ & $\begin{array}{l}\text { Localized: PSA > } 20 \mathrm{ng} / \mathrm{mL} \text {, } \\
\text { or GS }>7 \text { (ISUP grade } 4 / 5 \text { ), } \\
\text { or cT2c }\end{array}$ \\
\hline & & & $\begin{array}{l}\text { Locally Advanced: cT3-4 or } \\
\mathrm{cN}+\end{array}$ \\
\hline Very high & $\begin{array}{l}\text { Primary Gleason pattern } 5 \text {, or }>4 \text { cores with } \\
\text { grade group } 4 \text { or } 5 \text {, or clinical stage T3b-T4 }\end{array}$ & - & - \\
\hline
\end{tabular}

NCCN, National Comprehensive Cancer Network; AUA, American Urological Association; EAU, European Association of Urology; PSA, prostate-specific antigen; GGG, Gleason grade group; IRF, intermediate risk factor; GS, Gleason score; ISUP, International Society for Urological Pathology.

setting of metastatic disease (1-4). Additionally, early diagnosis of persistent or recurrent disease improves treatment outcomes, highlighting the importance of robust imaging for detection of LN metastasis after initial therapy (5). Accurate imaging has the potential to determine candidates for salvage $\mathrm{LN}$ dissection or targeted radiation therapy for the treatment of oligometastatic disease (6-8).

Current guidelines generally recommend evaluation for LN metastases using abdominal and pelvic cross-sectional imaging for all patients with unfavorable-intermediate or greater risk at time of diagnosis (Table 1) $(2,9)$. The goal of this imaging is to provide adequate staging that can guide patient counseling and treatment determination. $\mathrm{LN}$ detection is particularly important because pelvic $\mathrm{LNs}$ are believed to be the initial site of metastasis in PCa (10). Early LN detection has been shown to change therapy at the time of diagnosis and in the setting of recurrence, but there is still a need for large prospective randomized trials to more accurately assess the full impact of imaging modalities on PCa therapy and outcomes (7,8,11-13). Since
PCa metastasizes first to pelvic LN, cross sectional imaging to evaluate the nodes is important $(2,9)$.

MRI has an emerging role in PCa detection and is integrated in many current prostate biopsy protocols $(14,15)$. In that setting, it may be used in lieu of CT for nodal staging. Current guidelines state that both CT and MRI are appropriate cross-sectional imaging modalities for the identification of nodal metastasis (Table 2) $(2,9,16)$. There is an ongoing debate about the optimal imaging modality in PCa nodal staging, which has been further fueled by the development of newer molecular imaging techniques. Advanced imaging modalities, and their ability to detect PCa metastasis to LNs, will change the landscape of $\mathrm{PCa}$ staging (17-20). Herein, we aim to discuss common and emerging PCa LN imaging modalities, and summarize evidence and indications for their utility (Table 3).

\section{Methods}

A PubMed/Medline search [1990-2018] was conducted 
Table 2 Current imaging guidelines for staging of prostate cancer

\begin{tabular}{|c|c|c|c|c|}
\hline Guideline & \multicolumn{4}{|c|}{ Imaging modality } \\
\hline \multicolumn{5}{|c|}{ Pre-treatment } \\
\hline $\mathrm{NCCN}$ & $\begin{array}{l}\text { Pelvis }+/- \text { abdomen for } \\
\text { intermediate, high, and } \\
\text { very high-risk disease with } \\
\text { nomogram probability of } \\
\text { lymph node involvement } \\
>10 \%\end{array}$ & $\begin{array}{l}\text { Pelvis }+/- \text { abdomen for } \\
\text { Intermediate, high, and } \\
\text { very high-risk disease with } \\
\text { nomogram probability of } \\
\text { lymph node involvement } \\
>10 \%\end{array}$ & $\begin{array}{l}\text { Consider if initial bone } \\
\text { scan demonstrates } \\
\text { equivocal results }\end{array}$ & $\begin{array}{l}\text { Unfavorable intermediate } \\
\text { if T2 and PSA }>10 \mathrm{ng} / \mathrm{mL} \text {, } \\
\text { high and very high-risk } \\
\text { disease, any stage disease } \\
\text { with symptoms of osseous } \\
\text { metastasis }\end{array}$ \\
\hline AUA & $\begin{array}{l}\text { Consider for unfavorable } \\
\text { intermediate risk, perform } \\
\text { in high risk }\end{array}$ & $\begin{array}{l}\text { Consider for unfavorable } \\
\text { intermediate risk, perform } \\
\text { in high risk }\end{array}$ & Not indicated & $\begin{array}{l}\text { Consider for unfavorable } \\
\text { intermediate risk, perform } \\
\text { in high risk }\end{array}$ \\
\hline \multicolumn{5}{|c|}{ Post-treatment } \\
\hline $\mathrm{NCCN}$ & $\begin{array}{l}\text { Pelvis, abdomen, and } \\
\text { chest for PSA persistence/ } \\
\text { recurrence post RP; PSA } \\
\text { persistence/recurrence } \\
\text { or positive DRE and } \\
\text { candidate for local therapy } \\
\text { post RT }\end{array}$ & $\begin{array}{l}\text { Pelvis and abdomen } \\
\text { for PSA persistence/ } \\
\text { recurrence post RP; PSA } \\
\text { persistence/recurrence } \\
\text { or positive DRE and } \\
\text { candidate for local therapy } \\
\text { post RT }\end{array}$ & $\begin{array}{l}\text { Consider }{ }^{18} \mathrm{~F} \text {-fluciclovine or } \\
{ }^{11} \mathrm{C} \text {-choline in the setting of } \\
\mathrm{BCR} \text { after local treatment } \\
\text { for further evaluation of } \\
\text { soft tissue and bone }\end{array}$ & $\begin{array}{l}\text { PSA persistence/ } \\
\text { recurrence post RP; PSA } \\
\text { persistence/recurrence or } \\
\text { positive DRE after RT and } \\
\text { following progression after } \\
\text { initial recurrence }\end{array}$ \\
\hline
\end{tabular}

NCCN, National Comprehensive Cancer Network; AUA, American Urological Association; EAU, European Association of Urology; CT, computed tomography; MRI, magnetic resonance imaging; PET, positron emission tomography; PSA, prostate-specific antigen; ISUP, International Society for Urological Pathology; mpMRI, multi-parametric magnetic resonance imaging; RP, radical prostatectomy; DRE, digital rectal exam; RT, radiation therapy; ADT, androgen deprivation therapy; BCR, biochemical recurrence; PSMA, prostate-specific membrane antigen.

in August 2018 for articles related to LN imaging for PCa. The search was limited to studies published in English. Prospective and retrospective original research, systematic reviews, and meta-analyses were included. Meeting abstracts, editorials, and commentaries were excluded. Two reviewers assessed dimensions of evidence quality, in particular, risk of bias for each paper in each library. Preference was given to articles that provided detailed analysis comparing the imaging modalities yielding statistically significant findings. Included articles were 
Table 3 Summary of advantages and disadvantages of CT and MRI with or without PET

\begin{tabular}{|c|c|c|c|c|}
\hline $\begin{array}{l}\text { Imaging } \\
\text { modality }\end{array}$ & $\begin{array}{l}\text { Types of } \\
\text { imaging }\end{array}$ & Contrast agent/radiotracer & Advantage & Disadvantage \\
\hline CT & Anatomic & - & $\begin{array}{l}\text { Relatively inexpensive, well studied, } \\
\text { globally available, contrast material } \\
\text { is optional }\end{array}$ & $\begin{array}{l}\text { Low sensitivity and specificity for } \\
\text { PCa metastasis }\end{array}$ \\
\hline \multirow[t]{2}{*}{ PET } & $\mathrm{PET} / \mathrm{CT}$ & $\begin{array}{l}{ }^{11} \mathrm{C} \text { - or }{ }^{18} \mathrm{~F} \text {-choline, } \\
{ }^{11} \mathrm{C} \text {-acetate, and }{ }^{18} \mathrm{~F} \text {-FACBC }\end{array}$ & $\begin{array}{l}\text { Increased sensitivity and specificity } \\
\text { over conventional imaging, useful } \\
\text { for BCR at moderate and high PSA } \\
\text { levels }\end{array}$ & $\begin{array}{l}\text { Expensive, unclear clinical benefit } \\
\text { over conventional imaging, requires } \\
\text { additional equipment and contrast } \\
\text { agents }\end{array}$ \\
\hline & PSMA PET/CT & $\begin{array}{l}{ }^{68} \mathrm{Ga}-\text { or }{ }^{18} \mathrm{~F} \text {-labeled } \\
\text { PSMA targeting agents, } \\
{ }^{18} \mathrm{~F} \text {-DCFBC, and }{ }^{18} \mathrm{~F} \text {-DCFPyl }\end{array}$ & $\begin{array}{l}\text { High diagnostic accuracy, } \\
\text { diagnostic accuracy improved } \\
\text { compared to other PET tracers at } \\
\text { low PSA levels }\end{array}$ & $\begin{array}{l}\text { Expensive, unclear clinical benefit } \\
\text { over conventional imaging, requires } \\
\text { additional equipment and contrast } \\
\text { agents }\end{array}$ \\
\hline \multirow[t]{2}{*}{ MRI } & Anatomic & - & $\begin{array}{l}\text { Superior soft tissue contrast vs. CT, } \\
\text { contrast material is optional, well } \\
\text { studied, useful for primary prostate } \\
\text { ca imaging }\end{array}$ & $\begin{array}{l}\text { Expensive, low sensitivity and } \\
\text { specificity for PCa metastasis }\end{array}$ \\
\hline & DWI & - & $\begin{array}{l}\text { Mild improvements in diagnostic } \\
\text { accuracy compared to anatomic } \\
\text { imaging, contrast material optional, } \\
\text { well studied, useful for primary PCa } \\
\text { imaging }\end{array}$ & $\begin{array}{l}\text { Low sensitivity and specificity for } \\
\text { PCa LN metastasis, difficult to } \\
\text { create standardized ADC values }\end{array}$ \\
\hline
\end{tabular}

CT, computed tomography; MRI, magnetic resonance imaging; PET, positron emission tomography; PSMA, prostate-specific membrane antigen; BCR, biochemical recurrence; PCa, prostate cancer; DWI, diffusion weighted imaging; USPIO, ultra-small superparamagnetic iron oxide; ADC, apparent diffusion coefficient.

selected by the consensus of all authors.

\section{CT imaging}

Pelvic lymph node dissection (PLND) is the most accurate method to diagnose metastatic PCa to LN (1). However, there is still debate regarding the application, benefits, and necessary extent of PLND. Since PLND is associated with a small yet significant risk of complications, including the development of lymphocele or intraoperative injuries that could potentially result in longer hospital stays, some providers defer the PLND given the lack of clear therapeutic benefit of the intervention (1). Society guidelines are variable, but generally recommend performing PLND in patients based on nomogram-predicted risk of $\mathrm{LN}$ involvement or in higher-risk patients (21). Recent studies have examined the role of imaging in deciding to perform PLND in low-risk patients who would traditionally not be candidates for PLND, adding further uncertainty to decision-making (21). The debate over the need for PLND and associated risks highlights the potential value of highquality imaging for $\mathrm{LN}$ disease detection. 

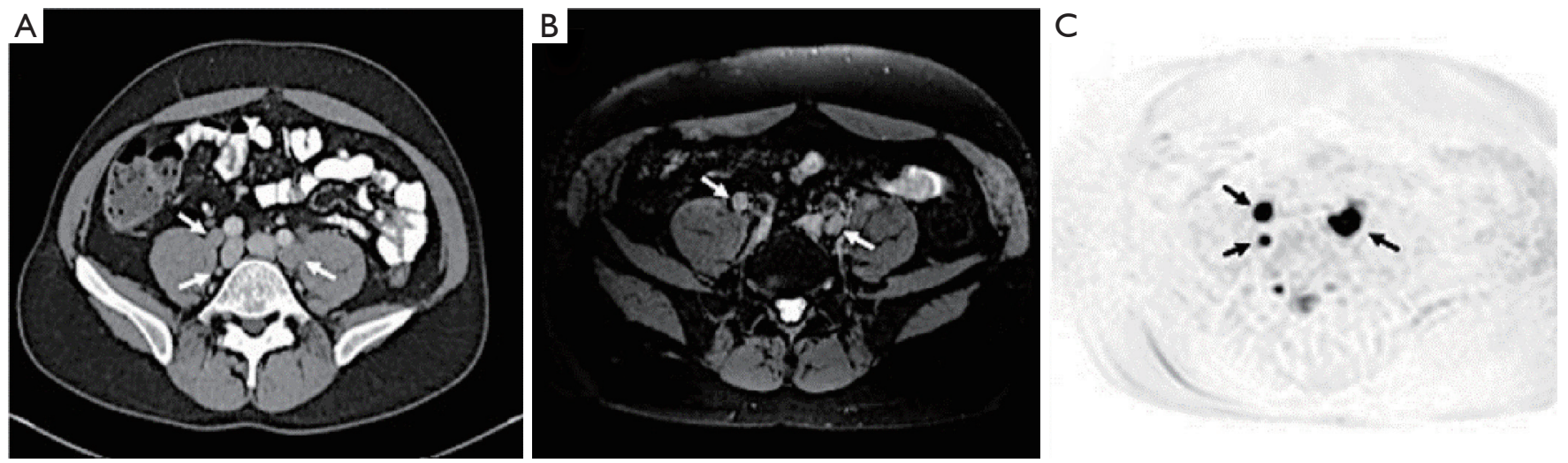

Figure 1 A 43 -year-old male with metastatic prostate cancer (S/P prostatectomy with a serum PSA =37 ng/mL). (A) There is bilateral common iliac lymph node enlargement at axial CT (white arrows); (B) axial fat saturated T1W MRI (white arrows); (C) axial b800 diffusion weighted MRI (black arrows). PSA, prostate-specific antigen; MRI, magnetic resonance imaging.

Abdominal and pelvic CT or MRI are utilized to assess LN involvement by examining size and morphology $(22,23)$. Determining positive nodes is difficult because many PCa metastatic LN demonstrate normal size, and enlarged LN may be benign $(22,23)$. Exact criteria to define a positive $\mathrm{LN}$ are variable, but a $\mathrm{LN}$ is generally considered abnormal if the short axis is $\geq 1 \mathrm{~cm}$ or if the $\mathrm{LN}$ is morphologically abnormal regardless of size (i.e., rounded, loss of fatty hilum, spiculated margins, asymmetric cortical thickening, heterogeneous, low signal intensity on T2w imaging) $(22,23)$ (Figure 1). Attempts to decrease objective and subjective anatomic thresholds at conventional CT or MRI to improve sensitivity result in unacceptable penalties to specificity.

The sensitivity of CT for the detection of metastatic $\mathrm{PCa}$ to $\mathrm{LN}$ using a short axis threshold of $\geq 1 \mathrm{~cm}$ is approximately $40 \%$; the exact sensitivity varies based on study criteria and individual patient risk (24). In a metaanalysis by Hövels et al., this criterion was determined to have a pooled sensitivity of $42 \%$ (95\% CI, 26-56\%) and a pooled specificity of $82 \%$ (95\% CI, 79-83\%) (24). The range of sensitivities across different studies is large: $5 \%$ to $94 \%(25-30)$. This variation highlights variability in patient populations and methodologies (24,31).

The sensitivity and specificity of CT for detection of metastatic $\mathrm{PCa}$ are low because $\mathrm{LN}$ size is a poor predictor of nodal metastasis. Normal patients have visible LNs. Therefore, for a $\mathrm{LN}$ to be positive at anatomic imaging, the tumor burden within a node has to reach a macroscopic quantity that distorts the normal nodal architecture. Non-enlarged LNs at cross-sectional imaging can harbor microscopic malignant disease that is below the resolution of the examination to image. Furthermore, not all enlarged LNs are malignant. Enlarged LNs may occur from multiple benign etiologies (32). The suboptimal diagnostic performance of CT challenges its role in the evaluation of patients with suspected metastatic PCa $(24,27)$. Although neither very sensitive nor specific for $\mathrm{LN}$ involvement, CT can be useful to suggest metastatic nodes when positive, to demonstrate extensiveness of bulk disease, to identify metastases to other sites such as liver or bones, and to help differentiate malignant from benign causes of abnormal uptake at bone scan (33).

\section{Positron emission tomography (PET)/CT}

Given the suboptimal diagnostic accuracy of CT for detecting metastatic $\mathrm{PCa}$, molecular imaging has been investigated for the assessment of metastatic disease in patients with $\mathrm{PCa}$ (Figure 2) (24). A variety of PET/CT radiotracers have been investigated for the diagnosis and staging of metastatic PCa. Direct comparisons between tracers are challenging due to differences in patient populations, disease severity, variations in study designs, and lack of a reliable reference standard (34). Well investigated radiotracers include ${ }^{11} \mathrm{C}$ - or ${ }^{18} \mathrm{~F}$-choline, ${ }^{11} \mathrm{C}$-acetate, ${ }^{18} \mathrm{~F}$-fluorocyclobutane-1-carboxylic acid $\left({ }^{18} \mathrm{~F}\right.$-FACBC or ${ }^{18} \mathrm{~F}$-fluciclovine), and radiotracers targeting PSMA. Of note, ${ }^{18} \mathrm{~F}$-fluorodeoxyglucose (FDG) is of limited use in PCa staging due to relatively low glycolytic activity of most $\mathrm{PCa}(34,35)$.

The cell uptake of ${ }^{11} \mathrm{C} /{ }^{18} \mathrm{~F}$-labeled choline tracers depends on the activity of the choline transport across the cell membrane. ${ }^{11} \mathrm{C}$-choline may also undergo further metabolic 

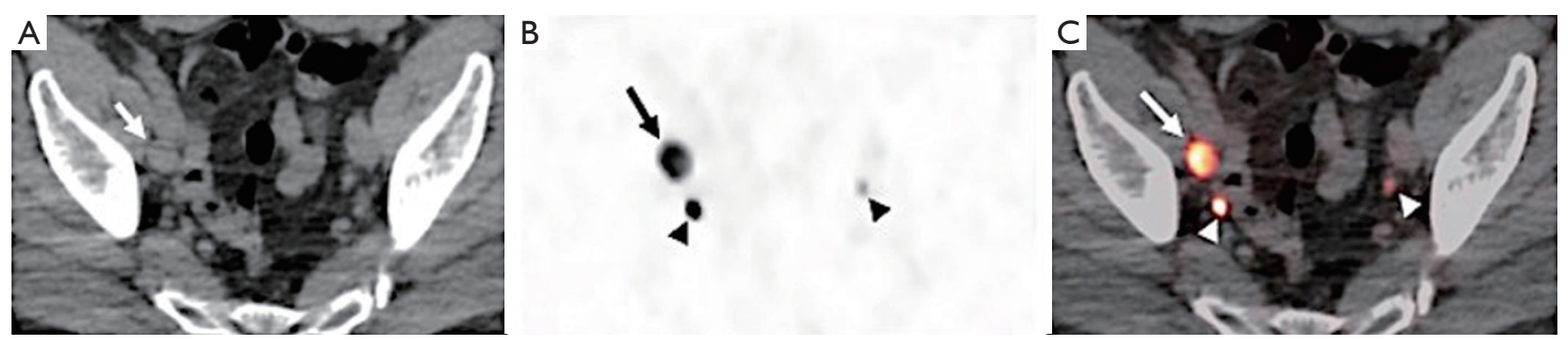

Figure 2 A 68-year-old male after radical prostatectomy with serum PSA =8.92 ng/mL. (A) Axial CT image shows an enlarged lymph node in the right iliac chain (arrow). (B) lymph node shows tracer uptake within the right iliac lymph node on axial ${ }^{18} \mathrm{~F}-\mathrm{DCFPyL} \mathrm{PET}$ and with (C) PET/CT images [black arrow in (B), white arrow in (C)]. Arrow heads show the tracer activity in ureters bilaterally in (B,C). Findings are consistent with prostate cancer metastasis to the right iliac chain (arrow) (courtesy of Dr. Esther Mena, from Molecular Imaging Program, NCI, NIH). PSA, prostate-specific antigen; PET, positron emission tomography; CT, computed tomography.

steps, which include integration into cell membranes. As a result, elevated uptake of choline radiotracers is not specific for $\mathrm{PCa}$, and may also be seen in many other malignancies as well as benign inflammatory processes (35). One advantage of ${ }^{11} \mathrm{C}$-choline is the lack of immediate urinary excretion, simplifying assessments of the prostatic bed. In contrast, ${ }^{18} \mathrm{~F}$-choline is excreted in the urine, obscuring visualization of the bladder wall and adjacent prostate bed. ${ }^{11} \mathrm{C}$-choline has a shorter half-life than ${ }^{18} \mathrm{~F}$-choline and thus requires an on-site cyclotron for use (36). ${ }^{11} \mathrm{C}$ - and ${ }^{18} \mathrm{~F}$-choline PET/CT have a broad range of sensitivities and specificities reported in the literature, but a recent meta-analysis found a pooled sensitivity of $62 \%$ and a pooled specificity of $92 \%$ for choline PET/CT detection of pelvic LN metastases (37). Choline PET/MRI has shown diagnostic advantages beyond MRI alone for the identification of PCa for fusion biopsy targeting and focal ablation $(38,39)$.

Acetate is a substrate for fatty acid synthase, which is reported to be overexpressed in $\mathrm{PCa}$ (40). Haseebuddin et al. found ${ }^{11} \mathrm{C}$-acetate-based PET/CT had a sensitivity and specificity for detecting LN metastasis of $68.0 \%$ and $78.1 \%$, respectively, in men with intermediate- or highrisk $\mathrm{PCa}$ and negative conventional imaging (41). The authors concluded that ${ }^{11} \mathrm{C}$-acetate was more sensitive than conventional imaging for positive LN detection (41). However, despite its apparent improvements over anatomic imaging alone, ${ }^{11} \mathrm{C}$-acetate has not gained widespread use as its diagnostic accuracy is suboptimal.

${ }^{18} \mathrm{~F}$-FACBC is an FDA-approved, synthetic l-leucine analog that demonstrates increased uptake in $\mathrm{PCa}(42)$ related to increased amino acid transport (34). Studies of ${ }^{18} \mathrm{~F}$-FACBC PET/CT for LN imaging are limited. In the primary setting (prior to initial treatment) one study found a sensitivity and specificity for detection of metastatic $\mathrm{LN}$ of $65.0 \%(40.8-84.6 \%)$ and $97.1 \%(85.1-99.9 \%)$, respectively (43). However, small metastatic LN ( $<5 \mathrm{~mm})$ are generally missed (43). In the setting of biochemical recurrence, Schuster et al. found a sensitivity and specificity of ${ }^{18} \mathrm{~F}$-FACBC PET/CT for the detection of extraprostatic recurrence of $55.0 \%$ and $96.7 \%$, respectively (44). A multicenter trial of 596 patients by Bach-Gansmo et al. found a positive predictive value (PPV) for extraprostatic disease of $92.3 \%$ (45). Preliminary evidence suggests high sensitivity but low-to-moderate specificity for detecting recurrent disease in the setting of BCR (46). Preliminary data available from studies directly comparing ${ }^{18} \mathrm{~F}$-FACBC with PSMA-based radiotracers suggest a superiority of PSMA-tracers over ${ }^{18} \mathrm{~F}$-FACBC for the identification of nodal and distant metastatic PCa.

In addition to the metabolic radiotracers, ligands to the so called prostate specific membrane antigen (PSMA) have been developed. PSMA, which functions as folate hydrolase (FOLH1) and glutamate carboxypeptidase II or N-acetylL-aspartyl-L-glutamate peptidase I, is a membrane protein expressed at low level by prostate epithelial cells $(47,48)$. PSMA PET tracers refer to radiolabeled small molecular inhibitors of PSMA that binds to the extracellular site of the PSMA protein. Most are radiolabeled with either Gallium-68 $\left({ }^{68} \mathrm{Ga}\right)$ or Fluoride-18 $\left({ }^{18} \mathrm{~F}\right)(49-51)$. Expression is relatively low on normal cells or in $\mathrm{BPH}$, but increases in PCa cells (48). Increased PSMA expression is correlated with higher grade tumors, elevated metastatic potential, and particularly hormone-refractory cancer $(47,48)$. While the majority of $\mathrm{PCa}$ overexpress PSMA, up to $8 \%$ of cancers 
may lack PSMA expression (52).

The utility of PSMA ligands for the identification of PCa in the setting of BCR, especially for men with low PSA levels, has been well established (51). Furthermore, their use in initial staging is now under investigation. Perera et al. performed a meta-analysis to determine the sensitivity and specificity of PSMA PET in the detection of LN metastasis, and reported a pooled sensitivity of $80 \%$ with a corresponding specificity of $97 \%$ on a per-lesion basis (20). Öbek et al. attempted to characterize the sensitivity and specificity of ${ }^{68} \mathrm{Ga}$-PSMA PET/CT compared to morphological imaging (CT or MRI) in high- and veryhigh-risk patients at primary staging. They found sensitivity and specificity of $56 \%$ and $86 \%$ in the whole cohort, respectively, which increased to $67 \%$ and $88 \%$ in patients who had 15 or more LN removed (17). The average size of LN harboring metastases that were missed by ${ }^{68} \mathrm{Ga}-$ PSMA PET/CT was $3.9 \pm 2.7 \mathrm{~mm}$ (median $4 \mathrm{~mm}$, range, $0.2-8 \mathrm{~mm}$ ), smaller than the minimum threshold necessary to identify a malignant node at morphologic imaging (17). They concluded that ${ }^{68} \mathrm{Ga}$-PSMA PET/CT was superior to morphological imaging for LN detection, but surgical dissection was still the primary method for LN staging pending further evidence and trials (17).

van Leeuwen et al. found sensitivity of $64 \%$ and specificity of $95 \%$ of ${ }^{68} \mathrm{Ga}$-PSMA PET/CT in intermediate and high risk PCa for primary staging (19). Of those positive LNs that were missed, the average size was $2.73 \pm 1.29 \mathrm{~mm}$ (19). Hijazi et al. retrospectively evaluated pelvic extended LN dissection (eLND) in the setting of BCR and high risk primary PCa detected by ${ }^{68} \mathrm{Ga}-\mathrm{PSMA}$ PET/CT (53). They found per node sensitivity and specificity of $94 \%$ and $99 \%$, respectively (53). A prospective trial to examine whether ${ }^{68} \mathrm{Ga}$-PSMA PET/CT changes patient management in the setting of high risk PCa or BCR found ${ }^{68} \mathrm{Ga}$-PSMA PET/ CT changed management decisions in $51 \%$ of patients (54). This effect was observed more often in patients with BCR (62\% with a change in management) compared to patients with high-risk primary $\mathrm{PCa}(21 \%$ with a change in management) (54). In a meta-analysis, Perera et al. found ${ }^{68} \mathrm{Ga}$-PSMA PET/CT positive scan rates were correlated with PSA levels. For PSA ranges of $<0.2,0.2-0.99,1.00$ 1.99 , and $>2 \mathrm{ng} / \mathrm{mL}$, positive scan rates were $42 \%, 58 \%$, $76 \%$, and $95 \%$, respectively (20). Bluemel et al. found that ${ }^{68} \mathrm{Ga}$-PSMA PET/CT detected disease in $43.8 \%$ (14 of 32 patients, $n=8$ in prostatic bed, $n=6$ in $\mathrm{LN}$ ) of patients with BCR who had negative ${ }^{18} \mathrm{~F}$-choline PET/CT (55). ${ }^{68} \mathrm{Ga}-$
PSMA PET/CT may be particularly useful when compared to other imaging modalities at PSA $<1 \mathrm{ng} / \mathrm{mL}$. In the same study, Bluemel et al. found that adding ${ }^{68} \mathrm{Ga}$-PSMA PET/CT to ${ }^{18} \mathrm{~F}$-choline PET/CT improved the detection rate in BCR to $61.5 \%$ compared to $46.1 \%$ in patients with PSA $\geq 0.2$ and $<1 \mathrm{ng} / \mathrm{mL}$ (55). In summary, there is growing evidence that PSMA PET/CT has high impact on clinical management in the setting of BCR, especially in cases of oligo-metastatic disease with potential for focal therapies (56).

Fendler et al. studied 635 patients with BCR and assessed the diagnostic accuracy, inter-reader reproducibility, and safety of ${ }^{68} \mathrm{Ga}$-PSMA PET/CT with lesions validated by histopathologic analysis (57). PPV was 84\% (95\% CI, $75-90 \%$ ) by histopathologic validation, with increased detection in patients with higher PSA: $38 \%$ for $<0.5 \mathrm{ng} / \mathrm{mL}$ $(\mathrm{n}=136), 57 \%$ for 0.5 to $<1.0 \mathrm{ng} / \mathrm{mL}(\mathrm{n}=79), 84 \%$ for 1.0 to $<2.0 \mathrm{ng} / \mathrm{mL}(\mathrm{n}=89), 86 \%$ for 2.0 to $<5.0 \mathrm{ng} / \mathrm{mL}(\mathrm{n}=158)$, and $97 \%$ for $\geq 5.0 \mathrm{ng} / \mathrm{mL}(\mathrm{n}=173, \mathrm{P}<0.001)(57) ; 256(40 \%)$ patients had extrapelvic disease, including 105 (17\%) with LN or soft tissue involvement, and 47 (7\%) with both LN and soft tissue and bone involvement (57).

Efforts have been made to radiolabel PSMA ligands with ${ }^{18} \mathrm{~F}$ instead of ${ }^{68} \mathrm{Ga}$ to improve spatial resolution and radiotracer half-life (68vs. 110 minutes, respectively) (58-61). A prospective trial using ${ }^{18} \mathrm{~F}$-DCFBC PSMA PET/CT in 17 patients with metastatic hormone-naïve and castrationresistant $\mathrm{PCa}$ found increased sensitivity of ${ }^{18} \mathrm{~F}$-DCFBC PSMA PET/CT compared to conventional imaging for detecting lesions (92\% vs. 71\%, respectively) (62). In a prospective study of ${ }^{18} \mathrm{~F}$-DCFPyl PSMA PET/CT in patients $(n=68)$ with $B C R$ and negative conventional imaging, Mena et al. found lesion detection rates of $15 \%(n=2 / 13), 46 \%(n=6 / 13), 83 \%(n=10 / 12)$, and $77 \%$ $(n=23 / 30)$ for patients with PSA levels of $>0.2$ to $<0.5,>0.5$ to $1.0,>1$ to 2.0 , and $\geq 2.0 \mathrm{ng} / \mathrm{mL}$, respectively (63). Thirtynine sites of recurrence were discovered in $\mathrm{LN}$ (63). A prospective phase II study by Gorin et al. of ${ }^{18} \mathrm{~F}$-DCFPyl PSMA PET in 25 men with localized high- or very-highrisk PCa prior to prostatectomy and pelvic LN dissection found a sensitivity and specificity of disease detection at the level of individual nodal packets of $66.7 \%$ and $92.7 \%$, respectively (64). A larger multicenter trial, which is no longer recruiting patients, is underway (ClinicalTrials.gov identifier number NCT02981368).

In addition to LN imaging, PSMA PET/CT has been shown to significantly outperform bone scan for the detection of bone involvement with sensitivity (98.7- 
$100 \%)$ and specificity $(88.2-100 \%)$ ranges superior to that of bone scan (86.7-89.3\% and $60.8-96.1 \%$, respectively; $\mathrm{P}<0.001)(65)$.

Overall, current evidence suggests that PET/CT imaging with PSMA ligands is promising and superior to conventional imaging in BCR. However, current evidence from PSMA ligands has mainly been obtained from retrospective data. Clearly well-controlled multi-center trials are necessary to determine a clinical benefit for BCR and initial staging to gain FDA approval for PSMA ligands. Current guidelines from the National Comprehensive Cancer Network (NCCN) and European Association of Urology (EAU) acknowledge the potential for PET/CT (especially newer agents), but currently recommend using PET/CT only in selected patients (Table 2) $(2,16)$. Detailed imaging recommendations in the preoperative and postoperative setting are shown in Table 2. In summary, both the NCCN and EAU guidelines conclude that PET/CT may be useful for detecting soft tissue metastases in the setting of BCR, and the NCCN states PET/CT may be used when initial bone scan demonstrates equivocal results $(2,16)$. The EAU mentions that while evidence suggests PET/CT is more sensitive for metastases than conventional CT, the clinical benefit and thereby cost-effectiveness of PET/CT is unclear at this time (2). In the setting of BCR, the diagnostic rate of choline PET/CT may be improved by selecting for patients who are most likely to show detectable disease. Treglia et al. found that stratifying for PSA kinetics (PSA doubling time $\leq 6$ months and PSA velocity $>1$ or $>2 \mathrm{ng} / \mathrm{mL}$ year) improved the diagnostic rate of choline PET/CT, suggesting that PSA kinetics in part could be used to stratify the need for metabolic imaging (66).

\section{Magnetic resonance imaging (MRI)}

MRI has good diagnostic performance for the detection and staging of locally advanced PCa (67-70). Preoperative identification of locally advanced and metastatic disease is important for patient counseling and treatment decisions, as this subset of patients is preferably treated with androgen-deprivation therapy with or without radiation (4). Similar to CT, MRI has poor sensitivity and specificity for LN metastases (4). This is because it relies on similar properties (shape, size). Up to $80 \%$ of PCa LN metastases do not meet threshold size criteria and are missed at MRI (71). A meta-analysis conducted by Hövels et al. found that the pooled sensitivity and specificity of MRI for
LN metastasis were $39 \%$ and $82 \%$, respectively (similar to CT) (24). Despite the limitations of MRI, there is a growing body of evidence that supports the use of MRI in the local staging of PCa in select patients (67). Given the relative redundancy in anatomic information (i.e., LN status) between CT and MRI, patients undergoing MRI for local staging may not need a separate pelvis CT for nodal staging assuming the MRI has at least one sequence that includes the entire pelvis in the field of view.

Diffusion weighted imaging (DWI) is a functional MRI technique that relies on tissue differences in water diffusivity to image abnormalities. The relative diffusivity can be expressed quantitatively with the apparent diffusion coefficient (ADC). Lower ADC values indicate less water diffusion, which is evident in the setting of tightly packed cells, purulent material, and hemorrhage (72). ADC mapping has been studied for imaging head and neck LN metastases (73), and for preoperative assessment of pelvic LN $(68,74)$. Unfortunately, in PCa, DWI MRI is still inaccurate for detecting $\mathrm{LN}$ metastases, regardless of size $(75,76)$. DWI provides only modest improvement for $\mathrm{LN}$ staging over conventional anatomic imaging (76). The limitations of DWI are multifold and include: an inability to characterize normal-size $\mathrm{LN}$, inaccurate $\mathrm{ADC}$ values due to partial volume effects and technical factors, suboptimal inter-rater and inter-site reproducibility, false negative results in necrotic nodes due to increased water diffusion, false positive results in reactive enlarged nodes, and artifacts related to motion and bowel gas $(68,74)$.

Thoeny et al. conducted a prospective study of 4,846 pelvic $\mathrm{LN}$ in 120 patients to evaluate the diagnostic performance of diffusion-weighted MRI in the detection of pelvic LN metastases in patients with clinical N0 prostate and bladder cancer (23). They found that DWI increased per-patient sensitivity for malignant nodes to $64-79 \%$ while maintaining a specificity of $84-85 \%$ (23). The authors stated this was possible, despite overlapping ADCs in small $\mathrm{LN}$ between malignant and benign nodes, because they used morphologic imaging in combination with DWI to reduce false positive results (23). The authors hypothesized that conflicting results between studies of DWI sensitivity, specificity, and accuracy may be due to differences in image analysis and patient populations. Overall, more evidence is necessary to understand the role of DWI in LN imaging for metastatic PCa. Methods and ADC thresholds are institution and machine dependent, making these results difficult to generalize. 

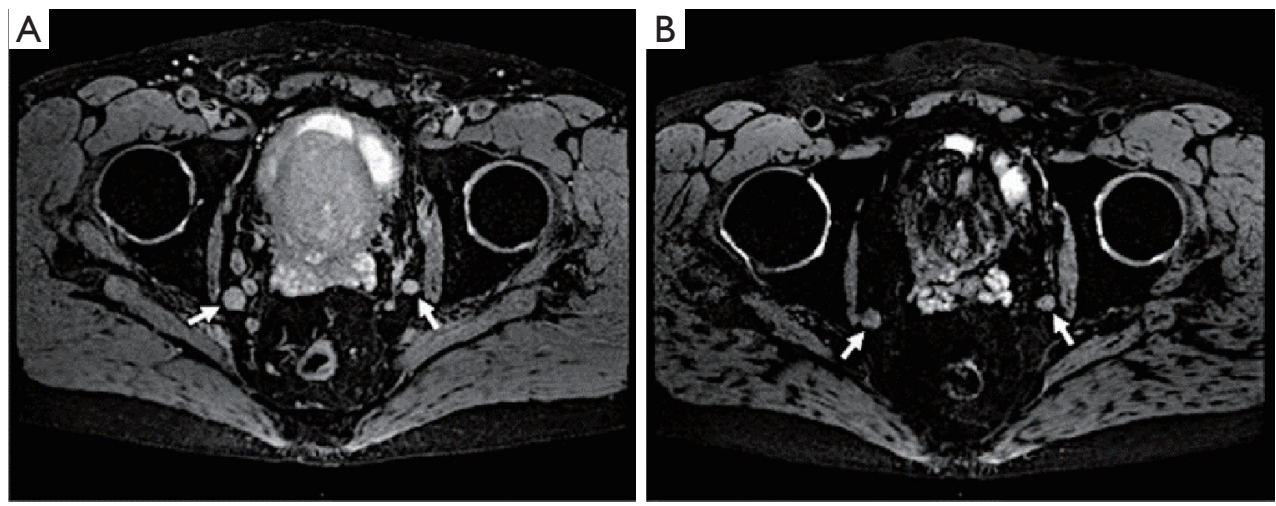

Figure 3 A 68-year-old male with Gleason 4+3 prostate cancer, serum PSA =56 ng/mL. (A) Axial T2*W MRI shows bilateral iliac lymph nodes (arrows). (B) $24 \mathrm{~h}$ post ferumoxytol injection axial T2*W MRI shows lack of ferumoxytol uptake within the iliac lymph nodes bilaterally (arrows). Findings are consistent with prostate cancer metastases (arrows) (courtesy of Dr. Baris Turkbey, from Molecular Imaging Program, NCI, NIH). PSA, prostate-specific antigen; MRI, magnetic resonance imaging.

\section{Ultra-small superparamagnetic iron oxide (USPIO) enhanced MRI}

Magnetic resonance lymphography utilizing USPIO particles has been utilized to improve the detection of occult LN metastases. This technique relies on iron nanoparticles taken up by macrophages residing in normal LN. Normal LN have more macrophages compared to malignant nodes because they have not been replaced by tumor cells. This property allows differentiation of benign and malignant LN with susceptibility-weighted MRI. Specifically, when susceptibility-weighted MRI is used, the iron particles cause signal loss in normal LN. The malignant LN have either no signal loss or heterogeneous signal loss because the tumor cells do not take up the iron (black LN: normal, gray or white LN: malignant) (77). In other words, USPIOenhanced MRI acts as a negative contrast agent, reducing the signal intensity of normal, non-metastatic LN (4).

This new modality has shown promising results, outperforming conventional CT and MRI in the detection of LN metastases with sensitivities between $65-92 \%$ and specificities ranging between 93-98\% (78-81). One study found sensitivity of $100 \%$ and specificity of $95.7 \%$, with the ability to detect some metastases $<2 \mathrm{~mm}$ in diameter (82). In another study, Harisinghani and colleagues conducted a prospective, single-center open label study investigating the use of ferumoxytol, a carboxymethyl dextran-based magnetic nanoparticle for the detection of locoregional LN (Figure 3) (82). In this pilot study, USPIO MRI demonstrated a significant reduction of the signal-to-noise ratio (SNR) in benign $\mathrm{LN}$ (change of $68.2 \%, \mathrm{P}<0.0001$ ) with minimal SNR change for malignant nodes (change of $8.5 \%, \mathrm{P}=0.16$ ). USPIO MRI demonstrated significantly lower signal intensity in benign $\mathrm{LN}$ compared to malignant LN (-37.8\% vs. $-4.7 \% ; \mathrm{P}<0.0001)$ (82). Additionally, the combination of diffusion-weighted MRI with USPIO demonstrated improved sensitivity, with $\mathrm{LN}$ detection rates of $87 \%$ in $\mathrm{LN}$ with short axes of $\leq 8 \mathrm{~mm}$ and $77 \%$ of $\mathrm{LN}$ with short axis of $\leq 3 \mathrm{~mm}$ (83). Unfortunately, multiple challenges currently exist in the use of USPIO. There is a lack of available agents; for example, ferumoxtran-10 is only available in the Netherlands, and the alternative ferumoxytol requires off-label use in the United States and has a black-box warning from the Food and Drug Administration (FDA) about fatal anaphylaxis (84). Other challenges include the necessity for multiple images over hours to days, which is difficult to manage logistically. Furthermore, the image analysis is subjective and labor intensive as all LN must be compared before and after drug administration (34).

\section{Conclusions}

Accurate nodal staging of $\mathrm{PCa}$ is important to guide treatment and inform patients. Despite significant advances in the field of cancer imaging, conventional imaging modalities remain the standard of care in the radiographic evaluation of patients with PCa according to national and international guidelines. Improvements in advanced imaging techniques are needed because conventional imaging has suboptimal diagnostic accuracy for nodal metastases. This is 
primarily due to an inability to detect cancer within normalsize LNs. Multiple technologies including new tracers, contrast agents, and imaging sequences have demonstrated improved detection over conventional modalities. More studies are necessary to better understand the clinical role, accuracy, and cost-effectiveness of newer imaging modalities, as existing studies are often small and have variable results. These advanced modalities are particularly exciting as investigators begin to explore not only their role in cancer detection, but also their potential for cancer therapy.

\section{Acknowledgments}

Funding: None.

\section{Footnote}

Conflicts of Interest: All authors have completed the ICMJE uniform disclosure form (available at http://dx.doi. org/10.21037/tau.2020.03.20). The authors have no conflicts of interest to declare.

Ethical Statement: The authors are accountable for all aspects of the work in ensuring that questions related to the accuracy or integrity of any part of the work are appropriately investigated and resolved.

Open Access Statement: This is an Open Access article distributed in accordance with the Creative Commons Attribution-NonCommercial-NoDerivs 4.0 International License (CC BY-NC-ND 4.0), which permits the noncommercial replication and distribution of the article with the strict proviso that no changes or edits are made and the original work is properly cited (including links to both the formal publication through the relevant DOI and the license). See: https://creativecommons.org/licenses/by-nc-nd/4.0/.

\section{References}

1. Fossati N, Willemse P-PM, Van den Broeck T, et al. The Benefits and Harms of Different Extents of Lymph Node Dissection During Radical Prostatectomy for Prostate Cancer: A Systematic Review. Eur Urol 2017;72:84-109.

2. Mottet N, Bellmunt J, Briers E, et al. EAU - ESTRO ESUR - SIOG Guidelines on Prostate Cancer. Arnhem, The Netherlands: EAU Guidelines Office; 2018.

3. Roach M, Marquez C, Yuo HS, et al. Predicting the risk of lymph node involvement using the pre-treatment prostate specific antigen and Gleason score in men with clinically localized prostate cancer. Int J Radiat Oncol Biol Phys 1994;28:33-7.

4. Lebastchi AH, Watson MJ, Russell CM, et al. Using Imaging to Predict Treatment Response in Genitourinary Malignancies. Eur Urol Focus 2018;4:804-17.

5. Cornford P, Bellmunt J, Bolla M, et al. EAU-ESTROSIOG Guidelines on Prostate Cancer. Part II: Treatment of Relapsing, Metastatic, and Castration-Resistant Prostate Cancer. Eur Urol 2017;71:630-42.

6. Suardi N, Gandaglia G, Gallina A, et al. Long-term Outcomes of Salvage Lymph Node Dissection for Clinically Recurrent Prostate Cancer: Results of a Singleinstitution Series with a Minimum Follow-up of 5 Years. Eur Urol 2015;67:299-309.

7. Ost P, Reynders D, Decaestecker K, et al. Surveillance or Metastasis-Directed Therapy for Oligometastatic Prostate Cancer Recurrence: A Prospective, Randomized, Multicenter Phase II Trial. J Clin Oncol 2018;36:446-53.

8. Siva S, Bressel M, Murphy DG, et al. Stereotactic Abative Body Radiotherapy (SABR) for Oligometastatic Prostate Cancer: A Prospective Clinical Trial. Eur Urol 2018;74:455-62.

9. Sanda MG, Cadeddu JA, Kirkby E, et al. Clinically Localized Prostate Cancer: AUA/ASTRO/SUO Guideline. Part I: Risk Stratification, Shared Decision Making, and Care Options. J Urol 2018;199:683-90.

10. Paño B, Sebastià C, Buñesch L, et al. Pathways of Lymphatic Spread in Male Urogenital Pelvic Malignancies. Radiographics 2011;31:135-60.

11. Dewes S, Schiller K, Sauter K, et al. Integration of (68) Ga-PSMA-PET imaging in planning of primary definitive radiotherapy in prostate cancer: a retrospective study. Radiat Oncol 2016;11:73.

12. Albisinni S, Artigas C, Aoun F, et al. Clinical impact of 68Ga-prostate-specific membrane antigen (PSMA) positron emission tomography/computed tomography (PET/CT) in patients with prostate cancer with rising prostate-specific antigen after treatment with curative intent: preliminary analysis o. BJU Int 2017;120:197-203.

13. Leeuwen PJ, Stricker P, Hruby G, et al. 68Ga-PSMA has a high detection rate of prostate cancer recurrence outside the prostatic fossa in patients being considered for salvage radiation treatment. BJU Int 2016;117:732-9.

14. Mehralivand S, Shih JH, Rais-Bahrami S, et al. A Magnetic Resonance Imaging-Based Prediction Model for Prostate Biopsy Risk Stratification. JAMA Oncol 2018;4:678.

15. Warlick C, Futterer J, Maruf M, et al. Beyond transrectal 
ultrasound-guided prostate biopsies: available techniques and approaches. World J Urol 2019;37:419-27.

16. NCCN Clinical Practice Guidelines in Oncology 2019: Prostate Cancer.

17. Öbek C, Doğanca T, Demirci E, et al. The accuracy of 68Ga-PSMA PET/CT in primary lymph node staging in high-risk prostate cancer. Eur J Nucl Med Mol Imaging 2017;44:1806-12.

18. Cantiello F, Gangemi V, Cascini GL, et al. Diagnostic Accuracy of 64 Copper Prostate-specific Membrane Antigen Positron Emission Tomography/Computed Tomography for Primary Lymph Node Staging of Intermediate- to High-risk Prostate Cancer: Our Preliminary Experience. Urology 2017;106:139-45.

19. van Leeuwen PJ, Emmett L, Ho B, et al. Prospective evaluation of 68 Gallium-prostate-specific membrane antigen positron emission tomography/computed tomography for preoperative lymph node staging in prostate cancer. BJU Int 2017;119:209-15.

20. Perera M, Papa N, Christidis D, et al. Sensitivity, Specificity, and Predictors of Positive 68 Ga-Prostatespecific Membrane Antigen Positron Emission Tomography in Advanced Prostate Cancer: A Systematic Review and Meta-analysis. Eur Urol 2016;70:926-37.

21. Porpiglia F, Manfredi M, Mele F, et al. Indication to pelvic lymph nodes dissection for prostate cancer: the role of multiparametric magnetic resonance imaging when the risk of lymph nodes invasion according to Briganti updated nomogram is $<5 \%$. Prostate Cancer Prostatic Dis 2018;21:85-91.

22. Zarzour JG, Galgano S, McConathy J, et al. Lymph node imaging in initial staging of prostate cancer: An overview and update. World J Radiol 2017;9:389-99.

23. Thoeny HC, Froehlich JM, Triantafyllou M, et al. Metastases in Normal-sized Pelvic Lymph Nodes: Detection with Diffusion-weighted MR Imaging. Radiology 2014;273:125-35.

24. Hövels AM, Heesakkers RAM, Adang EM, et al. The diagnostic accuracy of CT and MRI in the staging of pelvic lymph nodes in patients with prostate cancer: a metaanalysis. Clin Radiol 2008;63:387-95.

25. Levine M, Arger P, Coleman B, et al. Detecting lymphatic metastases from prostatic carcinoma: superiority of CT. AJR Am J Roentgenol 1981;137:207-11.

26. Engeler CE, Wasserman NF, Zhang G. Preoperative assessment of prostatic carcinoma by computerized tomography. Weaknesses and new perspectives. Urology 1992;40:346-50.
27. Gabriele D, Collura D, Oderda M, et al. Is there still a role for computed tomography and bone scintigraphy in prostate cancer staging? An analysis from the EUREKA-1 database. World J Urol 2016;34:517-23.

28. Briganti A, Abdollah F, Nini A, et al. Performance Characteristics of Computed Tomography in Detecting Lymph Node Metastases in Contemporary Patients with Prostate Cancer Treated with Extended Pelvic Lymph Node Dissection. Eur Urol 2012;61:1132-8.

29. Van Poppel H, Ameye F, Oyen R, et al. Accuracy of Combined Computerized Tomography and Fine Needle Aspiration Cytology in Lymph Node Staging of Localized Prostatic Carcinoma. J Urol 1994;151:1310-4.

30. Flanigan RC, McKay TC, Olson M, et al. Limited efficacy of preoperative computed tomographic scanning for the evaluation of lymph node metastasis in patients before radical prostatectomy. Urology 1996;48:428-32.

31. Lijmer JG, Mol BW, Heisterkamp S, et al. Empirical evidence of design-related bias in studies of diagnostic tests. JAMA 1999;282:1061-6.

32. Tiguert R, Gheiler EL, Tefilli MV, et al. Lymph node size does not correlate with the presence of prostate cancer metastasis. Urology 1999;53:367-71.

33. Tombal B, Lecouvet F. Modern Detection of Prostate Cancer's Bone Metastasis: Is the Bone Scan Era Over? Adv Urol 2012;2012:1-8.

34. Thoeny HC, Barbieri S, Froehlich JM, et al. Functional and Targeted Lymph Node Imaging in Prostate Cancer: Current Status and Future Challenges. Radiology 2017;285:728-43.

35. Wallitt KL, Khan SR, Dubash S, et al. Clinical PET Imaging in Prostate Cancer. Radiographics: A Review Publication of the Radiological Society of North America, Inc. 2017;37:1512-36.

36. Li R, Ravizzini GC, Gorin MA, et al. The use of PET/ CT in prostate cancer. Prostate Cancer Prostatic Dis 2018;21:4-21.

37. Eyben FE, Kairemo K. Meta-analysis of 11C-choline and 18F-choline PET/CT for management of patients with prostate cancer. Nucl Med Commun 2014;35:221-30.

38. Piert M, Shankar PR, Montgomery J, et al. Accuracy of tumor segmentation from multi-parametric prostate MRI and 18F-choline PET/CT for focal prostate cancer therapy applications. EJNMMI Res 2018;8:23.

39. Piert M, Montgomery J, Kunju LP, et al. 18F-Choline PET/MRI: The Additional Value of PET for MRI-Guided Transrectal Prostate Biopsies. J Nucl Med 2016;57:1065-70. 40. Grassi I, Nanni C, Allegri V, et al. The clinical use of 
PET with (11)C-acetate. Am J Nucl Med Mol Imaging 2012;2:33-47.

41. Haseebuddin M, Dehdashti F, Siegel BA, et al. 11C-Acetate PET/CT Before Radical Prostatectomy: Nodal Staging and Treatment Failure Prediction. J Nucl Med 2013;54:699-706.

42. Oka S, Hattori R, Kurosaki F, et al. A preliminary study of anti-1-amino-3-18F-fluorocyclobutyl-1-carboxylic acid for the detection of prostate cancer. J Nucl Med 2007;48:46-55.

43. Suzuki H, Inoue Y, Fujimoto H, et al. Diagnostic performance and safety of NMK36 (trans-1-amino-3-[18F] fluorocyclobutanecarboxylic acid)-PET/CT in primary prostate cancer: multicenter Phase IIb clinical trial. Jpn J Clin Oncol 2016;46:152-62.

44. Schuster DM, Nieh PT, Jani AB, et al. Anti-3-[(18)F] FACBC positron emission tomography-computerized tomography and (111)In-capromab pendetide single photon emission computerized tomography-computerized tomography for recurrent prostate carcinoma: results of a prospective clinical trial. J Urol 2014;191:1446-53.

45. Bach-Gansmo T, Nanni C, Nieh PT, et al. Multisite Experience of the Safety, Detection Rate and Diagnostic Performance of Fluciclovine (18F) Positron Emission Tomography/Computerized Tomography Imaging in the Staging of Biochemically Recurrent Prostate Cancer. J Urol 2017;197:676-83.

46. Mena E, Lindenberg LM, Choyke PL. New Targets for PET Molecular Imaging of Prostate Cancer. Semin Nucl Med 2019;49:326-36.

47. Davis MI, Bennett MJ, Thomas LM, et al. Crystal structure of prostate-specific membrane antigen, a tumor marker and peptidase. Proc Natl Acad Sci U S A 2005;102:5981-6.

48. Wright GL, Haley C, Beckett ML, et al. Expression of prostate-specific membrane antigen in normal, benign, and malignant prostate tissues. Urol Oncol 1995;1:18-28.

49. Meyer AR, Joice GA, Allaf ME, et al. Integration of PSMA-targeted PET imaging into the armamentarium for detecting clinically significant prostate cancer. Curr Opin Urol 2018;28:493-8.

50. Bailey J, Piert M. Performance of 68Ga-PSMA PET/ CT for Prostate Cancer Management at Initial Staging and Time of Biochemical Recurrence. Curr Urol Rep 2017;18:84.

51. Tan N, Bavadian N, Calais J, et al. Imaging of Prostate Specific Membrane Antigen Targeted Radiotracers for the Detection of Prostate Cancer Biochemical Recurrence after Definitive Therapy: A Systematic Review and Meta-
Analysis. J Urol 2019;202:231-40.

52. Bravaccini S, Puccetti M, Bocchini M, et al. PSMA expression: a potential ally for the pathologist in prostate cancer diagnosis. Sci Rep 2018;8:4254.

53. Hijazi S, Meller B, Leitsmann C, et al. Pelvic lymph node dissection for nodal oligometastatic prostate cancer detected by 68Ga-PSMA-positron emission tomography/ computerized tomography. Prostate 2015;75:1934-40.

54. Roach PJ, Francis R, Emmett L, et al. The Impact of 68Ga-PSMA PET/CT on Management Intent in Prostate Cancer: Results of an Australian Prospective Multicenter Study. J Nucl Med 2018;59:82-8.

55. Bluemel C, Krebs M, Polat B, et al. 68Ga-PSMA-PET/ CT in Patients With Biochemical Prostate Cancer Recurrence and Negative 18F-Choline-PET/CT. Clin Nucl Med 2016;41:515-21.

56. Jadvar H. Oligometastatic Prostate Cancer: Molecular Imaging and Clinical Management Implications in the Era of Precision Oncology. J Nucl Med 2018;59:1338-9.

57. Fendler WP, Calais J, Eiber M, et al. Assessment of $68 \mathrm{Ga}-$ PSMA-11 PET Accuracy in Localizing Recurrent Prostate Cancer: A Prospective Single-Arm Clinical Trial. JAMA Oncol 2019;5:856-63.

58. Cho SY, Gage KL, Mease RC, et al. Biodistribution, Tumor Detection, and Radiation Dosimetry of 18F-DCFBC, a Low-Molecular-Weight Inhibitor of Prostate-Specific Membrane Antigen, in Patients with Metastatic Prostate Cancer. J Nucl Med 2012;53:1883-91.

59. Szabo Z, Mena E, Rowe SP, et al. Initial Evaluation of [18F]DCFPyL for Prostate-Specific Membrane Antigen (PSMA)-Targeted PET Imaging of Prostate Cancer. Mol Imaging Biol 2015;17:565-74.

60. Chen Y, Pullambhatla M, Foss CA, et al. 2-(3-\{1-Carboxy5-[(6-[18F]fluoro-pyridine-3-carbonyl)-amino]-pentyl\}ureido)-pentanedioic acid, [18F]DCFPyL, a PSMA-based PET imaging agent for prostate cancer. Clin Cancer Res 2011;17:7645-53.

61. Kesch C, Kratochwil C, Mier W, et al. (68)Ga or (18)F for Prostate Cancer Imaging? J Nucl Med 2017;58:687-8.

62. Rowe SP, Macura KJ, Ciarallo A, et al. Comparison of Prostate-Specific Membrane Antigen-Based 18F-DCFBC PET/CT to Conventional Imaging Modalities for Detection of Hormone-Naive and Castration-Resistant Metastatic Prostate Cancer. J Nucl Med 2016;57:46-53.

63. Mena E, Lindenberg ML, Shih JH, et al. Clinical impact of PSMA-based 18F-DCFBC PET/CT imaging in patients with biochemically recurrent prostate cancer after primary local therapy. Eur J Nucl Med Mol Imaging 
2018;45:4-11.

64. Gorin MA, Rowe SP, Patel HD, et al. Prostate Specific Membrane Antigen Targeted 18F-DCFPyL Positron Emission Tomography/Computerized Tomography for the Preoperative Staging of High Risk Prostate Cancer: Results of a Prospective, Phase II, Single Center Study. J Urol 2018;199:126-32.

65. Pyka T, Okamoto S, Dahlbender M, et al. Comparison of bone scintigraphy and 68Ga-PSMA PET for skeletal staging in prostate cancer. Eur J Nucl Med Mol Imaging 2016;43:2114-21.

66. Treglia G, Ceriani L, Sadeghi R, et al. Relationship between prostate-specific antigen kinetics and detection rate of radiolabelled choline $\mathrm{PET} / \mathrm{CT}$ in restaging prostate cancer patients: a meta-analysis. Clin Chem Lab Med 2014;52:725-33.

67. Rooij M, Hamoen EHJ, Witjes JA, et al. Accuracy of Magnetic Resonance Imaging for Local Staging of Prostate Cancer: A Diagnostic Meta-analysis. Eur Urol 2016;70:233-45.

68. Raskolnikov D, George AK, Rais-Bahrami S, et al. The Role of Magnetic Resonance Image Guided Prostate Biopsy in Stratifying Men for Risk of Extracapsular Extension at Radical Prostatectomy. J Urol 2015;194:105-11.

69. Raskolnikov D, George AK, Rais-Bahrami S, et al. Multiparametric Magnetic Resonance Imaging and ImageGuided Biopsy to Detect Seminal Vesicle Invasion by Prostate Cancer. J Endourol 2014;28:1283-9.

70. Ahmed HU, El-Shater Bosaily A, Brown LC, et al. Diagnostic accuracy of multi-parametric MRI and TRUS biopsy in prostate cancer (PROMIS): a paired validating confirmatory study. Lancet 2017;389:815-22.

71. Heesakkers RAM, Hövels AM, Jager GJ, et al. MRI with a lymph-node-specific contrast agent as an alternative to CT scan and lymph-node dissection in patients with prostate cancer: a prospective multicohort study. Lancet Oncol 2008;9:850-6.

72. Roy C, Bierry G, Matau A, et al. Value of diffusionweighted imaging to detect small malignant pelvic lymph nodes at 3 T. Eur Radiol 2010;20:1803-11.

73. Vandecaveye V, De Keyzer F, Vander Poorten V, et al. Head and neck squamous cell carcinoma: value of diffusion-weighted MR imaging for nodal staging. Radiology 2009;251:134-46.

74. Vallini V, Ortori S, Boraschi P, et al. Staging of pelvic lymph nodes in patients with prostate cancer: Usefulness of multiple b value SE-EPI diffusion-weighted imaging on a 3.0 T MR system. Eur J Radiol Open 2015;3:16-21.

75. Budiharto T, Joniau S, Lerut E, et al. Prospective
Evaluation of 11C-Choline Positron Emission

Tomography/Computed Tomography and DiffusionWeighted Magnetic Resonance Imaging for the Nodal Staging of Prostate Cancer with a High Risk of Lymph Node Metastases. Eur Urol 2011;60:125-30.

76. Eiber M, Beer AJ, Holzapfel K, et al. Preliminary Results for Characterization of Pelvic Lymph Nodes in Patients With Prostate Cancer by Diffusion-Weighted MRImaging. Invest Radiol 2010;45:15-23.

77. Bellin MF, Lebleu L, Meric JB. Evaluation of retroperitoneal and pelvic lymph node metastases with MRI and MR lymphangiography. Abdom Imaging 2003;28:155-63.

78. Weissleder R, Moore A, Mahmood U, et al. In vivo magnetic resonance imaging of transgene expression. Nat Med 2000;6:351-4.

79. Weissleder R, Elizondo G, Wittenberg J, et al. Ultrasmall superparamagnetic iron oxide: an intravenous contrast agent for assessing lymph nodes with MR imaging. Radiology 1990;175:494-8.

80. Lewin M, Carlesso N, Tung CH, et al. Tat peptidederivatized magnetic nanoparticles allow in vivo tracking and recovery of progenitor cells. Nat Biotechnol 2000;18:410-4.

81. Fortuin AS, Smeenk RJ, Meijer HJM, et al. Lymphotropic nanoparticle-enhanced MRI in prostate cancer: value and therapeutic potential. Curr Urol Rep 2014;15:389.

82. Harisinghani MG, Barentsz J, Hahn PF, et al. Noninvasive detection of clinically occult lymph-node metastases in prostate cancer. N Engl J Med 2003;348:2491-9.

83. Birkhäuser FD, Studer UE, Froehlich JM, et al. Combined Ultrasmall Superparamagnetic Particles of Iron OxideEnhanced and Diffusion-weighted Magnetic Resonance Imaging Facilitates Detection of Metastases in Normalsized Pelvic Lymph Nodes of Patients with Bladder and Prostate Cancer. Eur Urol 2013;64:953-60.

84. Fortuin AS, Brüggemann R, Linden J, et al. Ultra-small superparamagnetic iron oxides for metastatic lymph node detection: back on the block. Wiley Interdiscip Rev Nanomed Nanobiotechnol 2018. doi: 10.1002/wnan.1471.

Cite this article as: Lebastchi AH, Gupta N, DiBianco JM, Piert M, Davenport MS, Ahdoot MA, Gurram S, Bloom JB, Gomella PT, Mehralivand S, Turkbey B, Pinto PA, George AK. Comparison of cross-sectional imaging techniques for the detection of prostate cancer lymph node metastasis: a critical review. Transl Androl Urol 2020;9(3):1415-1427. doi:10.21037/ tau.2020.03.20 